Thirteen blood films were examined, 300 cells being counted in each, and percentages found as shown in the following table:-

Percentage Results of Examination of Thirteen Blood Films.

\begin{tabular}{|c|c|c|c|c|c|c|}
\hline Cases. & $\begin{array}{l}\text { Poly- } \\
\text { morph. }\end{array}$ & $\begin{array}{l}\text { Small } \\
\text { lymph. }\end{array}$ & $\begin{array}{l}\text { Large } \\
\text { lymph. }\end{array}$ & $\begin{array}{l}\text { Mono- } \\
\text { nuclear. }\end{array}$ & $\begin{array}{c}\text { Eosino- } \\
\text { phil. }\end{array}$ & $\begin{array}{l}\text { Baso- } \\
\text { phil. }\end{array}$ \\
\hline $\begin{array}{r}1 \\
2 \\
3 \\
4 \\
5 \\
6 \\
7 \\
8 \\
9 \\
10 \\
11 \\
12 \\
13\end{array}$ & $\begin{array}{l}35 \cdot 0 \\
49 \cdot 6 \\
59 \cdot 0 \\
23 \cdot 0 \\
52 \cdot 0 \\
36 \cdot 4 \\
46 \cdot 0 \\
45 \cdot 7 \\
39 \cdot 6 \\
39 \cdot 4 \\
35 \cdot 3 \\
28 \cdot 0 \\
44 \cdot 4\end{array}$ & $\begin{array}{r}20 \cdot 0 \\
5.7 \\
16.0 \\
11.2 \\
19.0 \\
10 \cdot 0 \\
21.7 \\
7.3 \\
10.0 \\
7.3 \\
20.7 \\
29 \cdot 0 \\
21.6\end{array}$ & $\begin{array}{r}12 \cdot 0 \\
10 \cdot 0 \\
7.0 \\
25.2 \\
11.3 \\
7.2 \\
15 \cdot 3 \\
17.7 \\
13 \cdot 4 \\
13 \cdot 0 \\
19 \cdot 5 \\
15 \cdot 0 \\
6.6\end{array}$ & $\begin{array}{l}\text { Nil } \\
1 \cdot 0 \\
1 \cdot 0 \\
1 \cdot 0 \\
1 \cdot 0 \\
1 \cdot 0 \\
1 \cdot 3 \\
1 \cdot 0 \\
2 \cdot 0 \\
2 \cdot 0 \\
0 \cdot 7 \\
2 \cdot 0 \\
1 \cdot 0\end{array}$ & $\begin{array}{l}33 \cdot 0 \\
33 \cdot 7 \\
16 \cdot 0 \\
39 \cdot 6 \\
16.7 \\
35.4 \\
15 \cdot 7 \\
28 \cdot 3 \\
35 \cdot 0 \\
38 \cdot 0 \\
19.5 \\
25 \cdot 0 \\
26.4\end{array}$ & $\begin{array}{c}\text { Nil } \\
\because \cdot 0 \\
\mathbf{1} \cdot 0 \\
\text { Nil } \\
\Rightarrow, \\
\Rightarrow, \\
2 \cdot 0 \\
0 \cdot 3 \\
0 \cdot 3 \\
1 \cdot 0 \\
\text { Nil }\end{array}$ \\
\hline
\end{tabular}

The consistent and outstanding feature of the series is the high eosinophilic count ; the large lymphocytes also tend to be increased. The leucocytes in these 13 films did not appear to be very greatly increased; in the complete counts recorded earlier the slight leucocytosis is chiefly due to the great ousinophil increase.

\section{THE NORMAL INFANT'S CHEST.}

A PRELIMINARY REPORT ON THE X RAY EXAMINATION OF THE CHESTS OF HEALTHY INFANTS.

\section{BY J. F. P. PA T O N, M.B. EdiN.,} AND

\section{A. ROWAND, M.D. EDIN.}

(From the St. Andrews Institute for Clinical Research.)

THE necessity of obtaining a knowledge of the radiographic appearances of the healthy chest before attempting to endow shadows with pathological significance led us to begin the present investigation in the autumn of 1921. A considerable number of radiographs of healthy infants and children have now been obtained.

The present communication deals only with the radiographs of 12 infants of ages varying from 8 days to 15 weeks. These were selected as typical examples of health. They were all of the average weight at birth and without defects. They were all breast fed by healthy mothers, and were thriving well when photographed. With one exception, none of them had exhibited any symptoms of illness since birth, and in particular, no sign of nasal catarrh nor cough had been observed. The exception (Case 10) had a slight cold in the head with a little cough for about 10 days at the age of 6 weeks, and was photographed at 10 weeks, when all symptoms had subsided. None had marked tuberculous heredity, though in a few instances there were odd cases of tuberculous infection in the previous generation. (See details table.) They were drawn from all classes of the community.

\section{The Radiographic Conditions.}

Duplitised films with two fluorescent screens were employed. The exposures were all made with the same Coolidge tube at a distance of $60 \mathrm{~cm}$. in Cases 1 , $3,5,6,7,8,11 ; 55 \mathrm{~cm}$. in Cases $2,4,9,10 ; 50 \mathrm{~cm}$. in Case 12. The exposure was $1 / 10$ second. (V., 40,000; milliamps., 25.) The tube was placed in front of and the film behind the infant, which lay on its back. It was impossible to obtain precise orientation with such small infants or to secure each at the same phase of respiration.

Description of the Appearances Found.

There are wide variations in the size and position of the heart shadow in small infants. For example, in Case 9, aged 10 weeks, the chest shadow at the level of the seventh rib measures $104 \mathrm{~mm}$.; of this space the heart shadow occupies $65 \mathrm{~mm}$, while no less than $34 \mathrm{~mm}$. of it extend to the right of the middle line. In Case 1 , female, aged 8 days, the chest at the level of the seventh rib measures $100 \mathrm{~mm}$. ; the heart shadow at this level is $48 \mathrm{~mm}$. in diameter, while no part of it extends beyond the vertebral shadow to the right.

In the descriptions which follow we use the term " root region" for the area which extends vertically from the fifth rib to the eighth interspace, and

\begin{tabular}{|c|c|c|c|c|c|c|}
\hline $\begin{array}{l}\text { Case } \\
\text { No. }\end{array}$ & Sex. & Born. & $\begin{array}{r}\text { Wei } \\
\text { at bi }\end{array}$ & $\begin{array}{l}\text { ight } \\
\text { rth. }\end{array}$ & Family history. & $\begin{array}{l}\text { Age wher } \\
\text { X rayed. }\end{array}$ \\
\hline 1 & $\mathbf{F}$ & $1 / 11 / 21$ & $\frac{1 b .}{8}$ & $\begin{array}{l}o z . \\
12\end{array}$ & $\begin{array}{l}\text { Parents healthy ; } 1 \\
\text { other child, healthy; } \\
\text { no T.H. }\end{array}$ & $\begin{array}{c}8 \\
\text { days. }\end{array}$ \\
\hline 2 & M & $30 / 5 / 22$ & 11 & 0 & $\begin{array}{l}\text { no T.H. } \\
\text { Father bronchitic ; } \\
\text { mother healthy; no } \\
\text { T.H. ; 2 other chil- } \\
\text { dren, healthy. }\end{array}$ & $\begin{array}{c}11 \\
\text { days. }\end{array}$ \\
\hline 3 & $\mathbf{F}$ & $12 / 11 / 21$ & 7 & 4 & $\begin{array}{l}\text { Parents healthy ; } 1 \\
\text { other child, prema- } \\
\text { ture, now healthy ; } \\
\text { no T.H. }\end{array}$ & $\begin{array}{c}14 \\
\text { days. }\end{array}$ \\
\hline 4 & $\mathrm{M}$ & $15 / 5 / 22$ & 7 & 8 & $\begin{array}{l}\text { Parents healthy; } 1 \\
\text { otherchild, healthy; } \\
\text { maternal g r a nd- } \\
\text { aunt and possibly } \\
\text { grandmother T.B. }\end{array}$ & $\begin{array}{c}16 \\
\text { days. }\end{array}$ \\
\hline 5 & $F$ & $29 / 10 / 21$ & 8 & 4 & $\begin{array}{l}\text { Parents h eal th } \mathrm{H} \text {; } \\
\text { paternal aunt T.B. } \\
\text { hip; } 1 \text { other child, }\end{array}$ & $\begin{array}{c}3 \\
\text { weeks. }\end{array}$ \\
\hline 6 & M & $26 / 10 / 21$ & 7 & 12 & $\begin{array}{l}\text { Parents h e a thy ; } \\
\text { rheuwatic family } \\
\text { history; no T.H. } \\
2 \text { other children, } \\
\text { healthy, } 1 \text { with bent } \\
\text { legs. }\end{array}$ & $\begin{array}{c}3 \\
\text { weeks. }\end{array}$ \\
\hline 7 & $\mathbf{M}$ & $27 / 10 / 21$ & 8 & 4 & $\begin{array}{l}\text { Parents he al thy ; } \\
\text { paternal uncle dis- } \\
\text { charged army as } \\
\text { T.B., now well ; no } \\
\text { other children. }\end{array}$ & $\begin{array}{c}26 \\
\text { days. }\end{array}$ \\
\hline 8 & $\mathbf{F}$ & $13 / 9 / 21$ & 8 & 0 & $\begin{array}{l}\text { Father bealthy; } \\
\text { mother Graves's } \\
\text { disease, 1912, now } \\
\text { well; white leg } \\
\text { after both confine- } \\
\text { ments ; } 1 \text { other } \\
\text { child, healthy. }\end{array}$ & $\begin{array}{c}8 \\
\text { weeks. }\end{array}$ \\
\hline 9 & MI & $26 / 2 / 22$ & 6 & 8 & $\begin{array}{l}\text { Parents healthy; no } \\
\text { T.H.; no other } \\
\text { children. }\end{array}$ & $\begin{array}{c}10 \\
\text { weeks. }\end{array}$ \\
\hline 10 & $\mathbf{F}$ & $29 / 1 / 22$ & $\begin{array}{r}\text { No } \\
\text { weig. }\end{array}$ & thed. & $\begin{array}{l}\text { Father dyspeptic; } \\
\text { mother healthy no } \\
\text { T.H.; } 11 \text { other } \\
\text { children, of whom } 9 \\
\text { healthy, } 1 \text { dead } \\
\text { whooping - cough, } \\
1 \text { pneumonia. }\end{array}$ & $\begin{array}{c}10 \\
\text { weeks. }\end{array}$ \\
\hline 11 & $\mathbf{F}$ & $15 / 8 / 21$ & & 8 & $\begin{array}{l}\text { Parents h e a it h y } \\
\text { father's family sub: } \\
\text { ject to bronchitis; } \\
\text { no other children. }\end{array}$ & $\begin{array}{c}14 \\
\text { weeks. }\end{array}$ \\
\hline 12 & M & $17 / 7 / 21$ & 9 & 0 & $\begin{array}{l}\text { Parents ; } 3 \text { other } \\
\text { children, healthy, } 1 \\
\text { a twin, died in three } \\
\text { days. }\end{array}$ & $\begin{array}{c}15 \\
\text { weeks. }\end{array}$ \\
\hline
\end{tabular}

No previous illness in any case, with the exception of Case 10. This patient had nasal catarrh, slight cough 6 to 8 weeks. T.I. = tuberculous heredity.

horizontally about half the distance from the middle line to the chest margin in the fifth and sixth interspaces. Its outer boundary is roughly semilunar. Structurally this region includes the main bronchus and its principal divisions. The shadow pattern is distinct in this region. On the left side it is obscured by the heart shadow. In cases where the heart shadow extends far to the right, as it does in many infants, it is obscured on this side also.

The following are detailed descriptions of each case in the series:-

CASE 1.-Female, aged 8 days (see Fig. 1). Right chest From head of fifth rib there extends downwards and out wards to the head of the sixth rib a very distinct shadow. This is separated from the vertebral shadow in the space by a clearer crescentic area. From the outer border of this shadow very faint radiations spread upwards and outwards to second interspace. Definite smoky irregular shadowing extends downwards from seventh rib, and fainter linear shadows radiate downwards and outwards as far again as 
the main shadow extends from the middle line. Left chest: Shadows at root are obscured by heart sharlow, but definite upward and downward linear shadows, showing indication of arborescence in places, extend to the heart margin. One, passing downwards, almost reaches the phrenic shadow about $23 \mathrm{~mm}$. from middle line.

CASE 2.-Male, aged 11 days. Root shadows are obscured on both sides by heart shadow, though they can be faintly detected on the right. The heart shadow extends $25 \mathrm{~mm}$. to right of middle line. Right chest, beyond heart shadow On the right side distinct shadows pass obliquely down and out between eighth and ninth ribs, and some are visible between the ninth and tenth ribs close to spinal column. Left chest: On left side similar shadows are distinctly visible through heart shadow. In addition, marked linear shadows pass vertically upwards from level of fifth rib to the lower border of the third rib.

Cast 3.-Female, aged 14 days (see Fig. 2). Right chest Shadow extends from head of fifth rib to middle of sixth space. Its inner margin is continuous with heart shadow and it extends outwards two-fifths of the diameter of chest from midline to periphery. Below this a clear space extends vertically downwards to the diaphragm $5 \mathrm{~mm}$. from the vertebral shadow and $13 \mathrm{~mm}$. from middle line. Outside this shadows radiate obliquely towards the base, extending outwards to midway between vertebral shadow and the circumference of chest. A horizontal shadow extends outwards in fifth space almost to periphery. In the fourth interspace a definite circular shadow of about $1 \frac{1}{2} \mathrm{~mm}$. diameter is situated about $4 \mathrm{~mm}$. from heart shadow. Faint shadowing passing obliquely upwards and outward is evident in the third space and extending to the second Left chest: Definite shadowing, visible through heart shadow, is seen in the fifth space, from which definite radiations pass obliquely downwards and outwards and are visible to the ninth rib. Similar radiations, less marked, pass upwards and outwards, extending into the second space.

CASE 4.-Male, aged 16 days. Right chest: Heart shadow extends to $27 \mathrm{~mm}$. from midline and $19 \mathrm{~mm}$. from vertebral shadow. The root is thus obscured. Definite radiations pass downwards and outwards to the diaphragm about the middle of its extent, and in the sixth space there is a definite circular shadow situated $5 \mathrm{~mm}$. from heart shadow and $32 \mathrm{~mm}$. from the middle line. Shadows radiating obliquely upwards and outwards are visible in fourth and third spaces, extending faintly into second. Left chest : The root is obscured by heart shadow. Some oblique radiating shadows extending downwards and outwards are visible in sixth and seventh spaces outside heart margin. These pass faintly into the eighth space. Linear shadows are visible, $7 \mathrm{~mm}$. from vertebral shadow, extending nearly directly upwards from fifth rib almost to second rib, and directly upwards from fifth rib almost to second $\mathrm{r}$

CASE 5.-Female, aged 3 weeks (see Fig. 3). Right chest: The heart margin extends $8 \mathrm{~mm}$. beyond vertebral shadow. In fifth interspace, immediately outside this, a trace of shadow is visible, which becomes very definite in sixth space, extending $8 \mathrm{~mm}$. beyond the heart margin, and this is prolonged downwards through most of the seventh space. In centre of eighth interspace it is continuous with the heart shadow. From its lower margin faint lines of shadow radiate almost to diaphragm, extending as far outward as the middle of its surface. Left chest: The root shadows are obscured by the heart shadow, but through this radiations, passing downwards and outwards to the diaphragm in its inner third, are visible. A few faint radiating shadows passing obliquely upwards are visible in fifth, fourth, and third spaces outside heart margin.

CASI 6.-Male, aged 3 weeks. This patient turned into the right oblique position just as the exposure was made, with the result that the only definite finding is that in the left chest there are visible definite linear oblique downward shadows extending almost to the diaphragmatic shadow.

CAst 7.-Male, aged 26 days. Right chest: The heart shadow extends $7 \mathrm{~mm}$. from the vertebral shadow. Beyond this, in the sixth space, a mass of shadow extends obliquely outwards and downwards through the seventh space. A shadow, which appears continuous with this, is also present in eighth space, extending down to diaphragmatic shadow. Beyond the outer margin of this main shadow faint radiations are visible in seventh and especially eighth spaces, the latter extending to about the line of middle of diaphragm. In third, fourth, and fifth spaces definite shadows are present extending outwards from heart margin, some showing (fifth space) horizontal, and others (fourth and third spaces) oblique upward radiation. In the fourth space there is an oval shadow, long axis oblique upwards $3 \frac{1}{2} \mathrm{~mm} .1 \frac{1}{2} \mathrm{~mm}$. in measurement. Left lung: The region of the root is obscured by the heart, but faint oblique linear shadows can be detected through the heart shadow radiating upwards and downwards, extending in the latter direction to the diaphragm at junction of its outer and middle thirds.
CAst 8. Female, aged 8 weeks. Right chest: The heart extends $20 \mathrm{~mm}$. beyond vertebral shadow. The root shadon is obscured by this. A faint shadow occurs in fifth space continuous with the heart shadow. In sixth and seventh spaces shadowing is present, extending $10 \mathrm{~mm}$. from heart margin in the sixth space, but this is separated by a clear interval from heart shadow. Left chest: The root region is obscured by the heart shadow. From the sixth rib at the heart margin there extends upwards a vertical band of shadow, $5 \mathrm{~mm}$. in width, with a clear central area. Thi extends to the apex above, and appears to be prolonged through the heart shadow to the diaphragm. From the outer margin of this there radiates obliquely downwards and outwards to the diaphragm a faint linear streaking. This negative is blurred, movement having evidently occurred during exposure.

Case 9.-Male, aged 10 weeks. The heart shadow is large, pear-shaped, and more than half of it is to the right of th middle line. It extends $25 \mathrm{~mm}$. to the right of vertebral hadow at the level of the sixth rib, leaving only $16 \mathrm{~mm}$. clear lung shadow bevond it. Right chest: Through it. however, in the sixth interspace, a definite mass of shadowing is seen, from which radiate downwards four definite linea shadows arranged fan-wise. The group is separated by slightly clearer area from a second mass of shadow, close to the vertebral column, which extends downwards to the diaphragm, becoming broken up into streaks as it descends. Shadows extend outwards and downwards beyond the heart shadow to points opposite middle of diaphragm in seventh and eighth spaces. In the fifth space a horizontal band of shadowing can be distinguished through the heart shadow and extending beyond it. In third and fourth spaces oblique shadowing radiates upwards and outwards. Left chest The heart shadow obscures the root, but beyond it a fer linear shadows passing downwards and outwards are detected in seventh, eighth, and ninth spaces, almost reaching to the diaphragm. Distinct arborescent shadows are visible in third and fourth spaces, radiating outwards almost to the circumference of the chest.

CAse 10.-Female, aged 10 weeks (see Fig. 4). Right chest: Two-thirds of the heart shadow are to the right of the middle line, extending $25 \mathrm{~mm}$. from vertebral shadow. In fifth, sixth, and seventh spaces shadowing shows through this, and in the sixth space, from the outer margin of this mass, a very definite trunk of shadow passes a short distance downwards and outwards and breaks up into arborescent streaks. In fourth space, a little external to heart shadow, there is a small circular patch of shadow, about $1 \mathrm{~mm}$, in diameter. A similar spot of shadow is seen at upper margin of the fourth rib. Left chest: The heart shadow emerges from vertebral shadow at level of the sixth space, and extends in eighth space about $12 \mathrm{~mm}$. beyond vertebral shadow. In fifth and sixth space there is some well-marked shadowing with two circular denser patches in it. At the level of the seventh rib there radiates downwards and outwards from this a linear band of shadow which gets finer and less distinct towards the diaphragm, but can be traced almost to it Very faint shadows can be detected passing upwards in third and fourth spaces.

CASE 11.-Female, aged 12 weeks. Right chest: The heart shadow extends $10 \mathrm{~mm}$. to right of the vertebral shadow. From its margin at the level of the sixth interspace there extend downwards numerous arborescent streaks, several of which extend to diaphragmatic shadow. Some of them in the eighth space extend outwards to about $10 \mathrm{~mm}$. from the periphery of the lung. In the fifth interspace a definite patch of shadow occurs, slightly external to heart margin, and beyond this there are two patches, the outermost extending to $17 \mathrm{~mm}$. from chest margin. A few streaks in third and fourth spaces radiate upwards and outwards. Left chest : The root region is obscured by the heart, but in seventh, eighth, and ninth spaces radiating shadows can be detected through the heart shadow reaching almost to diaphragm, starting above at a point about $12 \mathrm{~mm}$. from vertebral shadow. Nothing can be detected through the heart shadow in upper part of chest.

CASE 12.-Male, aged 15 weeks. This negative is extremely thin. The heart shadow is mainly to the right, and nothing further can be detected on that side. On the left beyond the heart shadow some root shadowing is detected in sixth space.

\section{Summary.}

1. All cases examined show definite shadowing, not howogeneous, within an area extending from the fifth to the eighth ribs, and bounded externally br a semi-lunar line extending outwards, at the lerel of the sixth or seventh ribs, about three-sevenths of the total distance from the middle line to the circumference of the chest. This area contains the root of the lung It must be borne in mind that the infant's chest $j=$ proportionally shorter than the adult's. 


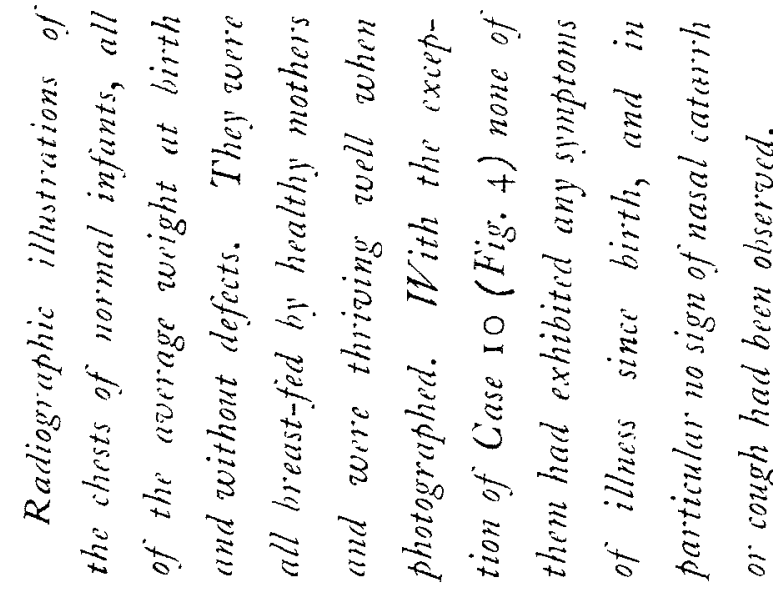
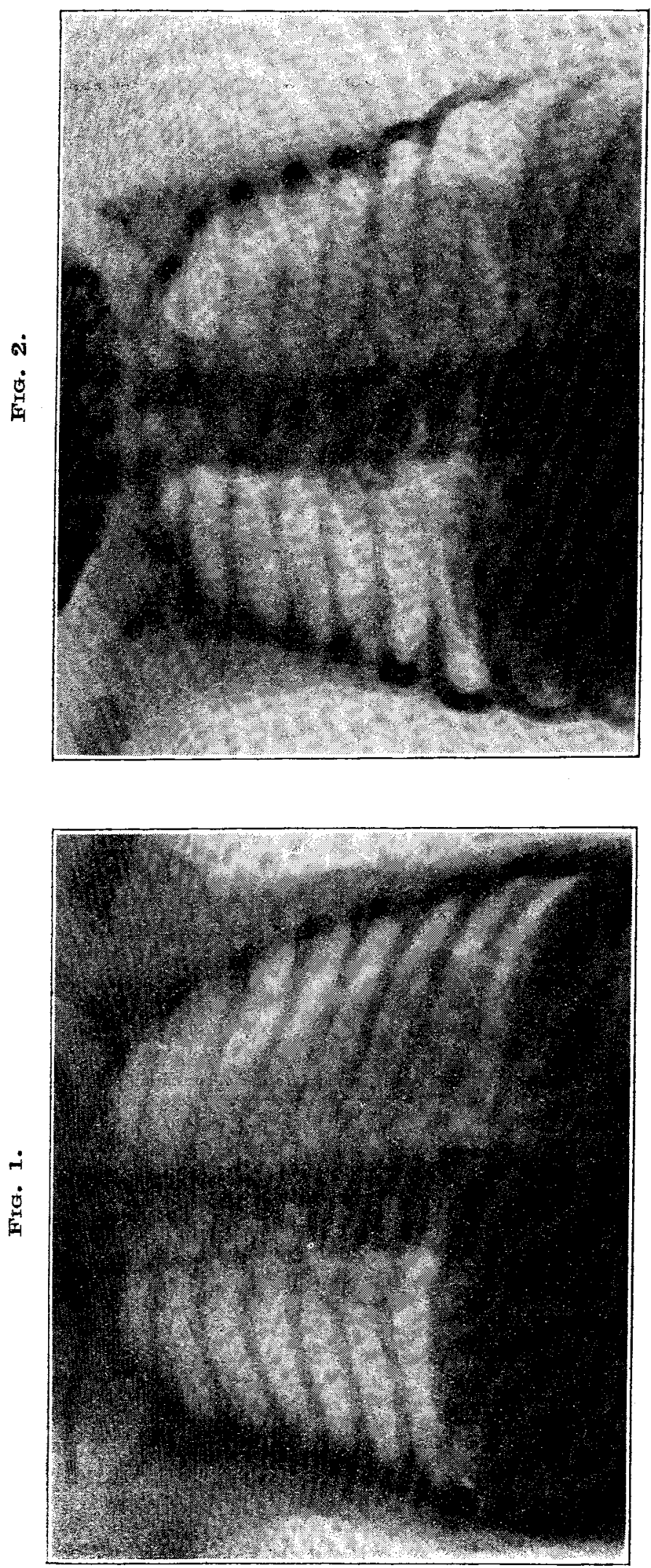
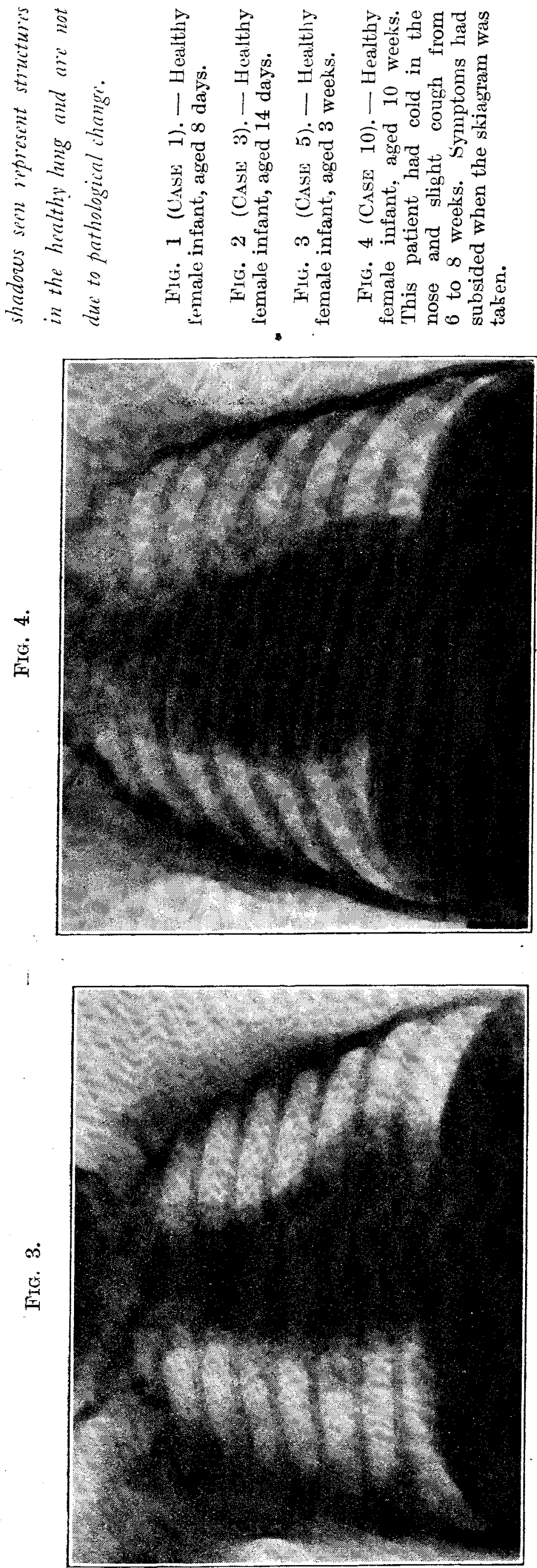
2. All cases examined show in varying degrec linear shadows, sometimes definitely arborescent, radiating from this area. Two main groups of these can readily be distinguished : (1) A basal group, mainly radiating downwards and outwards. The shadows in some instances extend to the shadow of the diaphragm. The upper shadows of this group pass horizontally, or almost horizontally, outwards, sometimes extending, in the sixth or seventh interspaces, rather more than half-way to the periphery from their origin. (2) An upper group, radiating upwards and outwards from about the level of the fifth interspace. These may in some instances be traced as high as the second rib. Between these groups there is a wedge-shaped area in which no shadows are usually visible, though occasionally (Cases Nos. 3,7,9) traces of horizontal streaking can be detected.

3. The position, size, and shape of the heart shadow in these healthy infants show very wide variations.

\section{Conclusions.}

1. As these results are obtained from healthy infants in whom no respiratory catarrhs have occurred, we conclude that the shadows seen represent structures in the healthy lung, and are not due to pathological change.

2. Their arborescent character noted in several cases suggests that they are thrown by the tissues of the normal bronchial tree, whether or not other structures such as blood vessels take any part in their formation.

3. It seems probable that this shadowing will become gradually more noticeable with the growth of the individual, and the appearances in these healthy infants suggest that the limits of the normal in older individuals must be much wider than is commonly supposed.

4. In several of our cases (Nos. $3,4,7,10$ ) minute dense circular shadows are observed. We avoid the use of the term nodular in the description of these because the word implies that such shadows are thrown by a nodule, which may or may not be the case. Such shadows could well be thrown by a cylindrical structure seen endwise. At any rate, in our cases their presence could not be due to a pathological deposit. If such a shadow as we have noted were increased in proportion to the size of the chest with advancing age, it would form a very noticeable feature in later pictures.

The valuable report to the National Tuberculosis Association (U.S.A.) on the $X$ Ray and Clinical Findings in the Normal Chest of Children from 6 to 10. years, published in THE LANCET of July 8 th, suggested to us that it would be of interest to communicate our results in the youngest of our series of infants now, for it is evident that in them we can exclude with practical certainty the possibility of catarrhal infection having any part in the production of the appearances. We shall follow the clinical histories of these infants and correlate them with radiographic findings at regular intervals.

We hope to publish a fuller account of our work in the reports of the Institute at a later stage.

We are indebted to Prof. D. Waterston for much valuable assistance, and to our radiographer, Mr. W. Smith, for the excellent negatives obtained in face of great difficulties. We also desire to express our indebtedness to the Medical Research Council for financial assistance towards the keeping of the records upon which this paper is based.

Post-graduate Training for Panel Doctors.On the occasion of his retirement from the post of a senior medical officer of the Scottish Board of Health to take up his duties as Professor of Preventive Medicine in the Queen's University, Kingston, Ontario, Dr. J. R. Currie was recently entertained to dinner by the Scottish Association of Insurance Committees. In thanking the chairman, Mr. J. Grieve, for making him a presentation, Dr. Currie spoke optimistically of medical benefit. He thought that a requirement that every doctor in a national insurance service should periodically undergo post-graduate training in order to keep up to date would be useful. He trusted that whatever developments took place in panel practice, the insurance committees might continue in office and in touch with medical benefits, since they carried on valuable public work.

\section{RADIUM AS A CURATIVE AGENT FOR TUBERCULOUS GIANDS.}

BY ECIIITN S. MOLYNEUX, M.R.C.S. ENG., HON. SURGEON TO THE WARNEFORD HOSPITAL, LEAMINGTON.

Evise since the discovery of radium its therapeutic properties have been a subject fascinating both to the medical profession and the laity. New uses are still being found for this powerful agent, and it would appear that the study of this science, far from having reached the limits of its application, is still only in its early stages. The surrical and medical treatment of tuberculous adenitis has been so unsatisfactory that in 1913-14 I thought I would see what could be done for this complaint by radium. As a result of these investigations I am convinced that the day of radical operation will soon be past, nor will it any longer be necessary to send children thus affected for prolonged periods of rest at the seaside, which often interfere seriously with their education. The unsightly scars that disfigure the necks of so many girls can also now be avoided. A cure can be promised to sufferers from tuberculous adenitis, early or advanced, if they consent to have the treatment properly carried out. The treatment is perfectly safe, provided that scrupulous attention is paid to the technique. I say this because recently a few cases have come under my notice where harm instead of good has been done by the administra tion of wrong doses of radium. During the period named I treated a considerable number of cases of every grade-some early cases, others with large caseating masses, and several with suppuration and secondary infection-and in every instance the swellings, and even old sinuses, simply faded away.

In no case where suppuration had not already occurred was any scar left. The skin was sometimes a little red for a few weeks from the effect of the secondary beta rays thrown off from the screen covering the radium; more will be said about this later. The redness always disappeared. The one disadvantage which may prevent this treatment becoming general is the initial cost of the radium and the ease with which applicators are damaged. Since my demobilisation from the R.A.M.C. I have had an opportunity of examining many patients whom I treated in 1913-14. In none of them can I find any signs of recurrence in the glands I treated then, nor have I heard of any recurring in other patients whom I have not since seen. One patient lately developed tuberculosis in a different group of glands; this I have already cured. In cases of doubtful diagnosis it has been my practice to remove a small piece of affected gland and have sections cut.

Technique.

It is unnecessary to go to the length of describing all the initial experiments and the concentrations of radium used. The following is the technique I now employ: The applicators used are square flat ones. A convenient size is $2 \mathrm{~cm}$. square, containing $15 \mathrm{mg}$. of radium bromide. I sometimes employ applicatoris about twice this size, 1 square in. containing the same amount of radium. To give a patient the same dose of radium with the larger applicator the length of exposure is double that with the smaller one.

The radium is spread out on the applicator, which is made of silver $3 \mathrm{~mm}$. thick. It must be mixed with some basis, to cause the radium to adhere to the applicator evenly and to prevent loss. I used to employ a special form of varnish with this object, but varnish perishes and is easily cracked if the applicator should be dropped, with consequent loss of part of the radium; recently I have used applicators in which the radium is incorporated with a form of cement instead of varnish, and these are less liable to damage. The applicator has over it a screen of $1 \mathrm{~mm}$. of silver, then a layer of lint, and finally a couple of layers of thin gutta-percha tissue tied orer the whole to prevent any soiling of the screen or the radium. The gutta-percha tissue can be renewed when the applicator is used for a different patient. 